\title{
Commemorating Geoffrey Raisman: a great neuroscientist and one of the founders of neurorestoratology and the IANR
}

This article was published in the following Dove Press journal: Journal of Neurorestoratology

Ying $\mathrm{Li}^{\prime}$

Pawel Tabakow ${ }^{2}$

Daqing $\mathrm{Li}^{\prime}$

Hongyun Huang ${ }^{3}$

On behalf of the International Association of Neurorestoratology

'Spinal Repair Unit, Department of Brain Repair and Rehabilitation, UCL Institute of Neurology, London, UK; ${ }^{2}$ Department of Neurosurgery, Wroclaw Medical University, Wroclaw, Poland; ${ }^{3}$ Institute of Neurorestoratology, General Hospital of Armed Police Forces, Beijing, People's Republic of China
Correspondence: Hongyun Huang Institute of Neurorestoratology, General Hospital of Armed Police Forces, Yongding Road No.69, Haidian District, Beijing 100039, People's Republic of China

Email hongyunh@gmail.com
One year ago (January 27, 2017), the sad news that Life Honorary President of the International Association of Neurorestoratology (IANR), Geoffrey Raisman (Figure 1) had passed away shocked all our association members. We could hardly hide our grief. Besides expressing our grief and condolences to his wife, Vivian; his daughter, Ruth; and all his family, the Core Administration members communicated among each other via email and made a proposal to rename the Youth Forum of the Annual Conference, to the Raisman Youth Forum of the Annual Conference. The fourth IANR Council Board meeting in Argentina on September 29, 2017 approved this motion, and decided to establish the Raisman Neurorestoratology Foundation and to write an article commemorating him to be published in the Journal of Neurorestoratology. This commemorative article is divided into three parts: 1) his students and colleagues Daqing Li and Ying Li introduce his life and work; 2) his collaborating partner Pawel Tabakow introduces the process of their clinical trial; and 3) Hongyun Huang on behalf of the IANR introduces Geoffrey Raisman's contribution to neurorestoratology and IANR. All individuals in the included images have provided written informed consent for the images to be published.

\section{In remembrance of Geoffrey Raisman - our mentor} Daqing Li and Ying Li

Professor Geoffrey Raisman was born into a Jewish family in Leeds, North England in 1939. His father, Harry Raisman was a tailor, one of 13 children of Lithuanian parents who came to Britain to escape the pogroms of late $19^{\text {th }}$ century Eastern Europe. His mother, Celia Narunsky was the only girl and eldest of six siblings. Living in a deprived Jewish area of Leeds, Geoffrey's parents saw education as the path to success and freedom. They strongly supported and encouraged Geoffrey in his learning from the earliest age. At an early age Geoffrey showed a great interest in science, of which biology and chemistry engrossed him most (personal communication, Ruth Partington-Temple February 2017).

Geoffrey won a scholarship to Pembroke College, Oxford to study medicine when he was 17 after attending Roundhay Grammar School. He worked in the Department of Human Anatomy at Oxford between 1965 and 1974 after his postgraduate studies.

Geoffrey was a neuroscientist who loved the neuroanatomy and always had tremendous curiosity in the ultrastructure of the nervous system. He was a pioneer and expert in his field. He was best known for his work on synaptic plasticity, neuroendocrinology, and axonal regeneration, repair of spinal cord injuries (SCI), and glaucoma. Against 


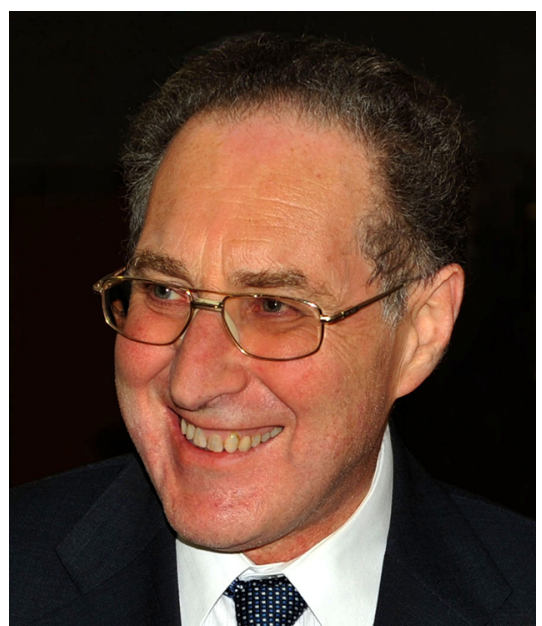

Figure I Geoffrey Raisman.

the general view that the adult central nervous system (CNS) was unable to regenerate, and there was no possibility of recovery after injury, he suggested regeneration and repair in the brain and spinal cord would be possible one day, with his discovery in 1969 that the new synapses could be formed to repopulate the denervated sites which were vacated due to the degeneration of the original afferent fibres by lesion. ${ }^{1}$ He described his finding as an anatomical revelation of the phenomenon of "neuronal plasticity". When his view that neuronal plasticity could lead to repair and recovery from CNS injuries was first published, after he had hesitated for a few years, it met with encouragement from some scientists in the field such as JZ Young and Pat Wall. It became controversial indeed, as expected, both in the field and the public world. But he soon gained much support from his colleagues around the world, and his findings were later confirmed by other scientists. Today neuronal plasticity or neuroplasticity in neurogenesis, learning and memory, CNS restoration after injuries or neurodegenerative diseases are widely studied.

In 1974 Geoffrey and his Oxford team moved to the National Institute for Medical Research, Medical Research Council, London where he became the head of the Division of Neurobiology, one of the youngest heads at the time. During that time Geoffrey developed the "pathway theory" that the white matter of the CNS is like a pathway with special arrangement of the cellular components - once it is disrupted by injury, such as SCI, growth of the regenerating fibers is obstructed. The theory was against the view in trend at the time that the white matter itself is inhibitory to axonal growth. He believed that reconstruction of the damaged white matter"the pathway" is essential for repair of the injured CNS.

In 1985 Geoffrey described how olfactory ensheathing cells (OECs) "open doors" for newly formed nerve fibers in the nose to enter the CNS. In 1987 we joined his team and together with Geoffrey, we carried out some pioneering research, discovering that damaged nerves in the CNS could be repaired. Taking advantage of this unique door-opening capability of OECs, we showed that transplantation of OECs into the damaged spinal cord in experimental models did indeed repair the disrupted pathway, lead to regeneration of damaged nerve fibers and result in the restoration of the lost functions. The article was first published in Science in 1997. ${ }^{2}$ It was the first experiment to show that damaged CNS axons can regenerate through lesions in the white matter tract.

Geoffrey was always enthusiastically committed to translating his research to the benefit of patients. In 2005, he and the team joined the Department of Brain Repair and Rehabilitation at the UCL Institute of Neurology for the purpose of translating the research work into clinical application, and there he established a dedicated Spinal Repair Unit at Queen Square (Figure 2). He was Professor of Neural Regeneration at UCL from 2005 and Chair of Neural Regeneration from 2012.

The OEC study also led to a joint clinical trial with a Polish neurosurgeon Pawel Tabakow and his team at Wroclaw Medical University, Poland. In 2014 the first patient, with a complete severance of the thoracic spinal cord caused by a stab, received transplantation of his own OECs. Professor Raisman visited the university hospital many times before the operation, and he was present in the operating theatre (Figure 3). The cells were placed via multiple injections above and below the injury. The severed spinal cord stumps with a gap of $11 \mathrm{~mm}$ were bridged with four segments of nerve from the patient's sural nerve. The operation enabled the patient to gain significant neurological recovery of sensation and voluntary movement, he can now get out of his wheelchair and ride a tricycle.

The wider application of OECs has also been investigated. In 2012, with his team at University College London, collaborating with the UCL Institute of Ophthalmology and Southwest Hospital, at the Third Military Medical University in Chongqing, China, Geoffrey described the protective effect of OECs in an experimental glaucoma model. The discovery led to a plan to translate this research to clinical application which, it is hoped, will help many sufferers regain sight. Raisman noticed, from electromicroscopy study in a glaucoma project, that there is a special type of glial cell in the region of the optic nerve head, surrounding the optic nerve axons; he named them fortified astrocytes. He suggested that the fortified astrocytes were responsible for mechanical support of the optic nerve head, for removing excess fluid, and for providing direct metabolic support to the axons. Together 


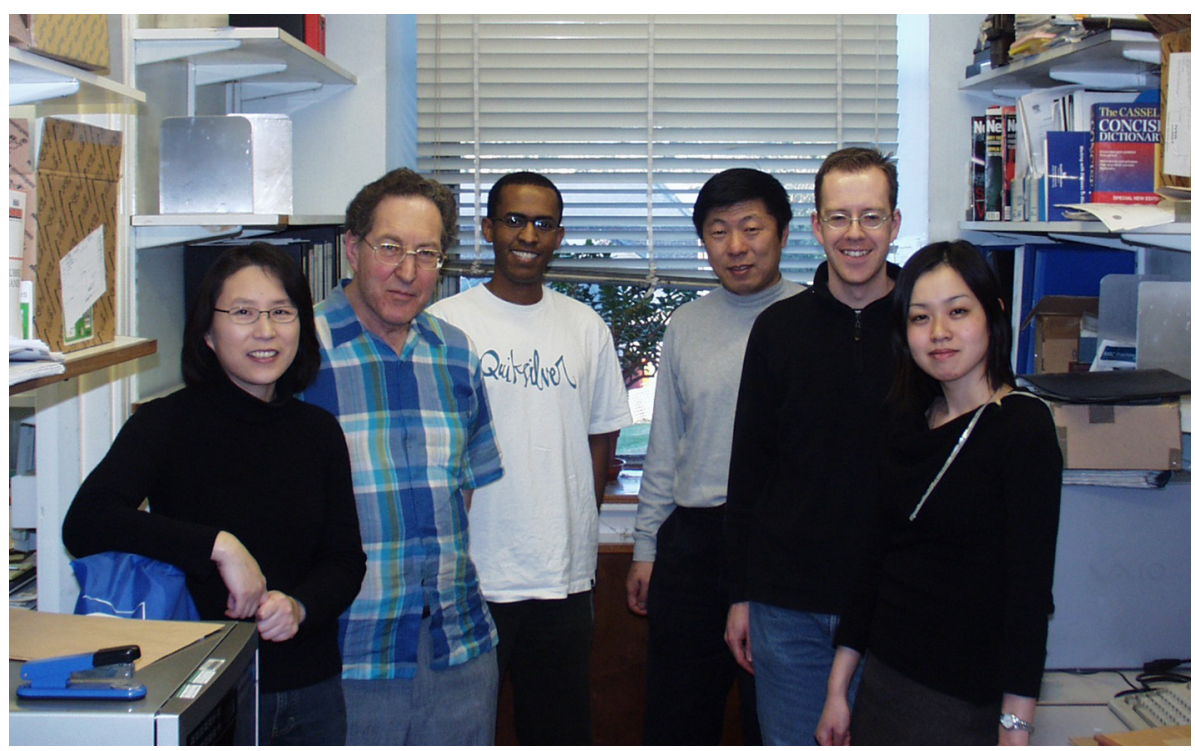

Figure 2 This photo was taken in 2005 with Raisman's team members after moving to UCL Institute of Neurology at Queen Square, London

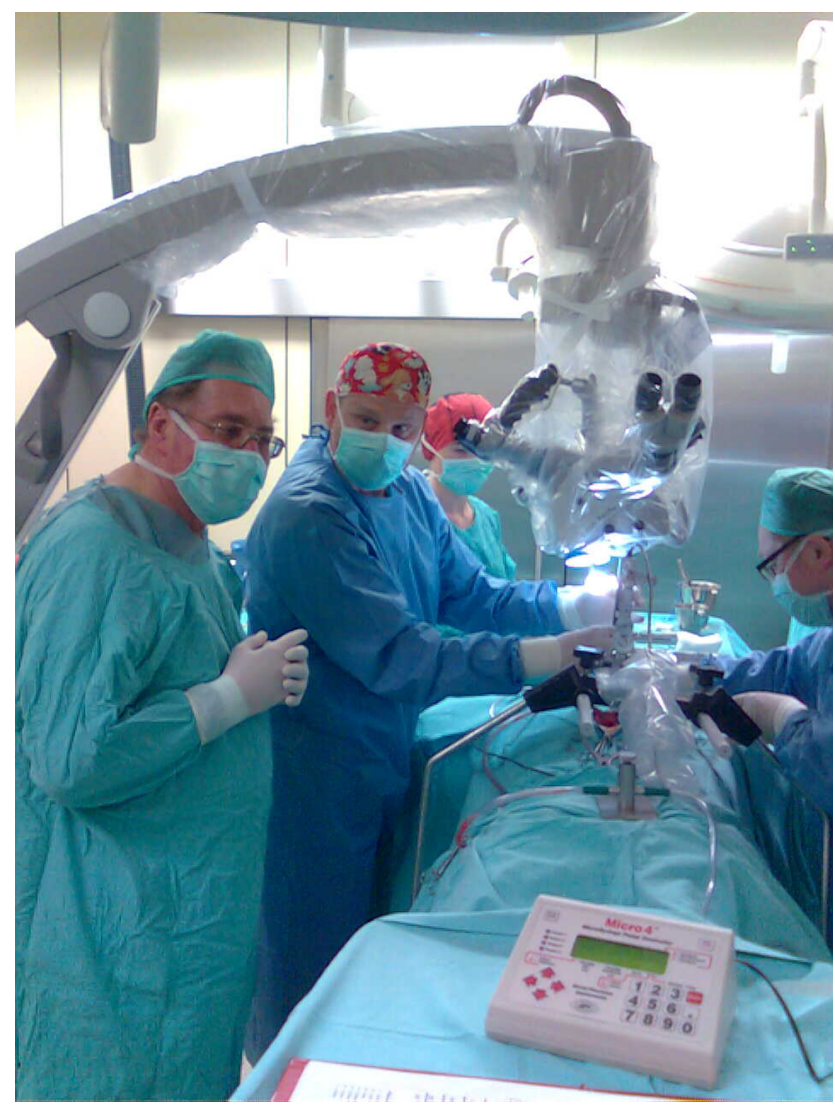

Figure 3 Geoffrey taking part, for the first time, in an experimental spinal cord reconstruction surgery in 2010 at Wroclaw University Hospital, Wroclaw, Poland.

with his team and his collaborators, Raisman described that the constant pressure and mechanical changes associated with eye movements can be buffered by the specialized structure and called this the energy theory of glaucoma, which published in $2015 .^{3}$ There are a few other theories about the cause of this disabling condition, the energy hypothesis is supported with current ideas on glial support of axonal metabolism and is an important contribution to understanding a common and distressing condition. Geoffrey also showed that OECs transplanted into the region of the optic nerve head of a rat can reduce the loss of axons and the damage to its astrocytes caused by raised intraocular pressure.

Geoffrey told us that he was the only neuroscientist from the West who could speak some Chinese in the 1980s, and this was why he was chosen by the British Council to be the first of only a few scientists to visit China after the Cultural Revolution ended. He continued to forge strong scientific links between the two countries for the rest of his career. We met him at Shanghai Institute of Physiology, Chinese Academy of Sciences in the early 1980s and joined his team in 1987. We were very lucky to have the opportunity to study our $\mathrm{PhD}$ under his supervision. We worked with him for nearly 30 years and made many important findings together in the neuroscience field. Geoffrey was not only our mentor, but also a long-term colleague, and true friend. It was not always easy to work with him because he always aimed high, thought more, and asked for more. We had arguments pretty often about the research, but he always respected our thoughts and views, although he might not agree. One of the hardest times working with him was when writing up a paper. He was a master of writing in terms of the language and presentation. It was often torturous for us to go through the process, but in the end we were all happy since the final results were often an excellent product. At the time of pursuing publication, 
he stood his feet firmly on quality rather than numbers. We travelled together quite a lot and we benefited so much from his amazing knowledge of the history, language and cultural background of the visited countries.

Geoffrey received numerous prizes and awards for his contribution to neuroscience, among these, the British Neuroscience Association Award for Outstanding Contribution to British Neuroscience in 2004; he was elected a fellow of the Royal Society in 2001 and awarded the Reeve-Irvine medal in 2005; he was awarded the Life Honorary President of the IANR in 2010.

Geoffrey had many interests outside science, including art, music, literature, history and other cultures. He was very talented with languages and was multilingual, among these languages both classical and modern Chinese. We were very impressed with his Chinese and his understanding of Chinese classical philosophy and poems. We learned a lot from him. He was a great companion and was a favorite mentor for junior researchers and students. His lectures were always well received around the world, especially among young audiences with whom he was always friendly, humble and encouraging. Geoffrey was also very interested in writing and wrote a book The Undark Sky: A Story of Four Poor Brothers ${ }^{4}$ in which he describes his family and his early life.

Geoffrey Raisman was a truly an exceptional and gifted person, and his death represents a major loss to his friends and the field of neurorestoratology. He will be missed greatly by us and many others.

\section{A farewell to Geoffrey Raisman - from bench to bed}

Pawel Tabakow

I would like first to express my deep condolences to Geoffrey Raisman's family. I am shocked by the fact that he has passed away, and believed to the end that he would win the battle with the disease in the same way he coped with many other difficulties in his life.

I had the extreme pleasure of knowing Geoffrey for 12 years (Figure 4) and to cooperate with him in the field of neurorestoratology. The innovative clinical approach my team developed to treat paralysis was the result of more than 40 years of intense laboratory preclinical work of Geoffrey and his team. Geoffrey was among the first to describe, in $1985,{ }^{5}$ when I was just 10 years old, the regenerationpromoting properties of OECs in the olfactory system of mammals. Since 1985, he has performed a substantial

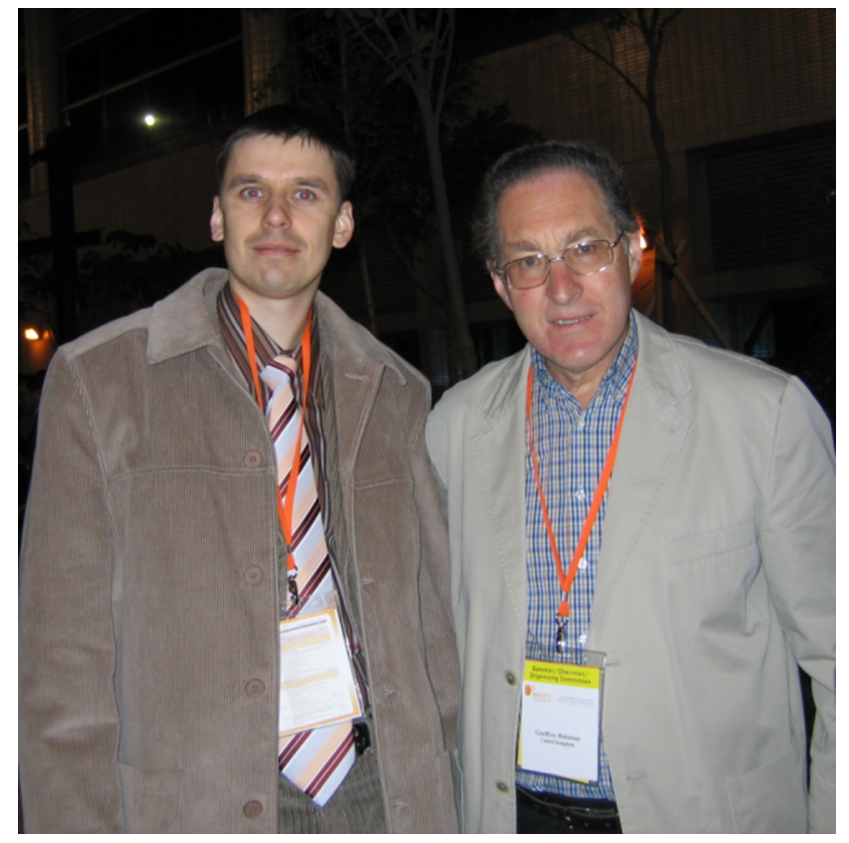

Figure 4 Pawel Tabakow's first meeting with Geoffrey during the First International Spinal Cord Injury Treatments \& Trials (ISCITT) Symposium, Hong Kong, 17-20 December 2005.

number of experiments in rats, showing histologically, neurophysiologically and clinically that OECs can "open the door" in the CNS for axon regeneration. I started in 1998 as a medical student, to follow the research of Geoffrey. Being fascinated by his results, I decided to dedicate my clinical career to neurosurgery and to translate the preclinical results of Geoffrey in the treatment of patients with complete SCIs. Our team of specialists in neurosurgery, neurobiology, neurology, neurophysiology and physiotherapy performed a Phase I clinical trial between 2008 and 2012, evaluating the safety and feasibility of transplantation of autologous OECs from the olfactory mucosa in three patients with thoracic paraplegia. ${ }^{6}$ We were following the scientific protocol of Geoffrey's team, concerning OEC-isolation, culture and preparation for transplantation. We developed a therapeutic protocol based on Geoffrey's philosophy in a way to make it feasible in human patients. The breakthrough in our research came in 2012 when our teams, Polish and English, worked together to treat successfully a patient with thoracic spinal cord transection (Figure 5). We showed that the "pathway hypothesis" he described is behind the observed miraculous neurological recovery in our patient (Figure 6). ${ }^{7}$ Geoffrey believed that central neurons have the intrinsic ability for regrowth, but the spatial astroglial response after SCI prevents axon elongation. This finding was against all other scientific theories of neuroregeneration described to date 


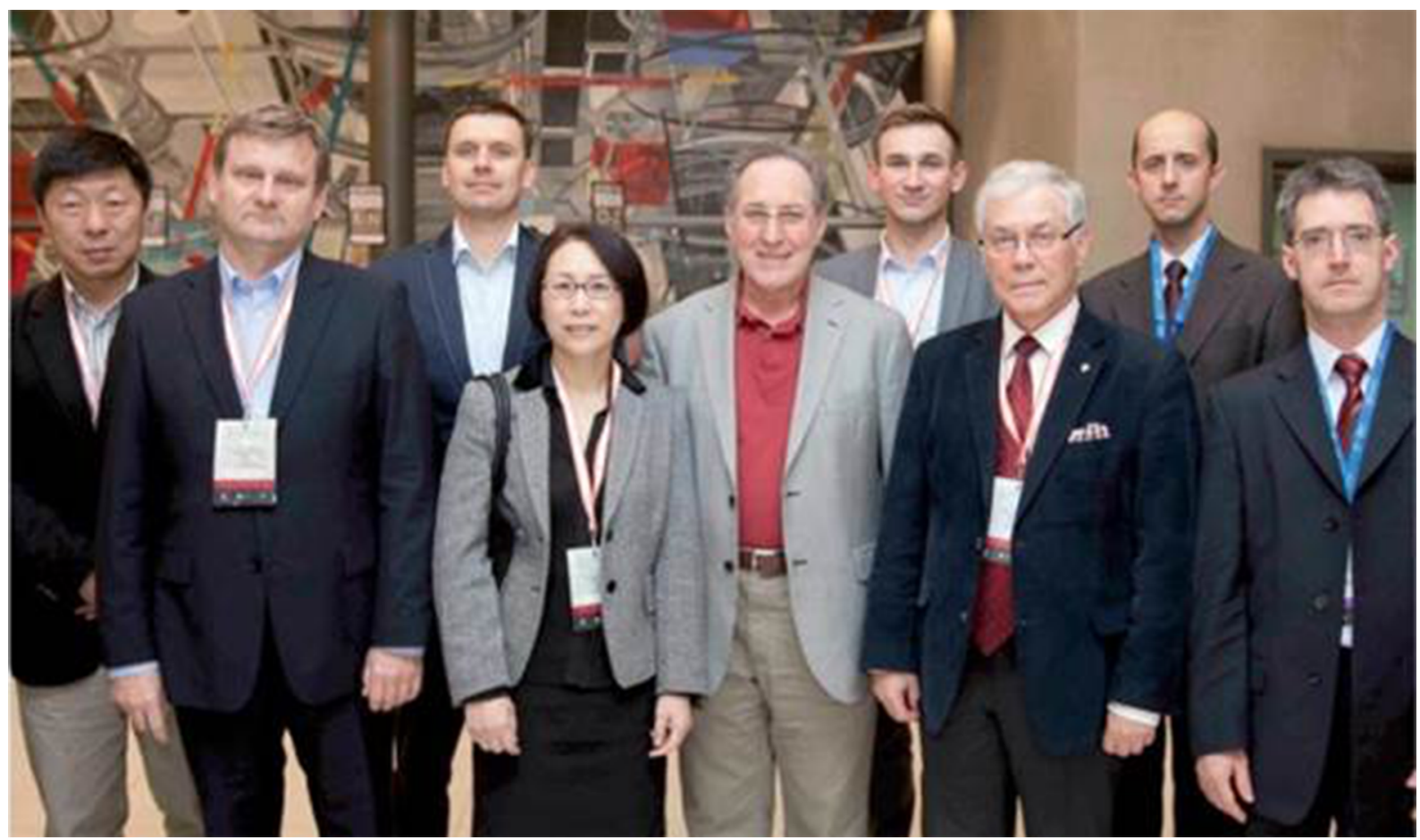

Figure 5 The Polish-English neuroregeneration research team during a conference in Lodz, Poland in 2013. Standing from left: Daqing Li, Bogdan Czapiga, Pawel Tabakow, Ying Li, Geoffrey Raisman, Marcin Czyz, Wlodzimierz Jarmundowicz, Dariusz Szarek, Wojciech Fortuna.

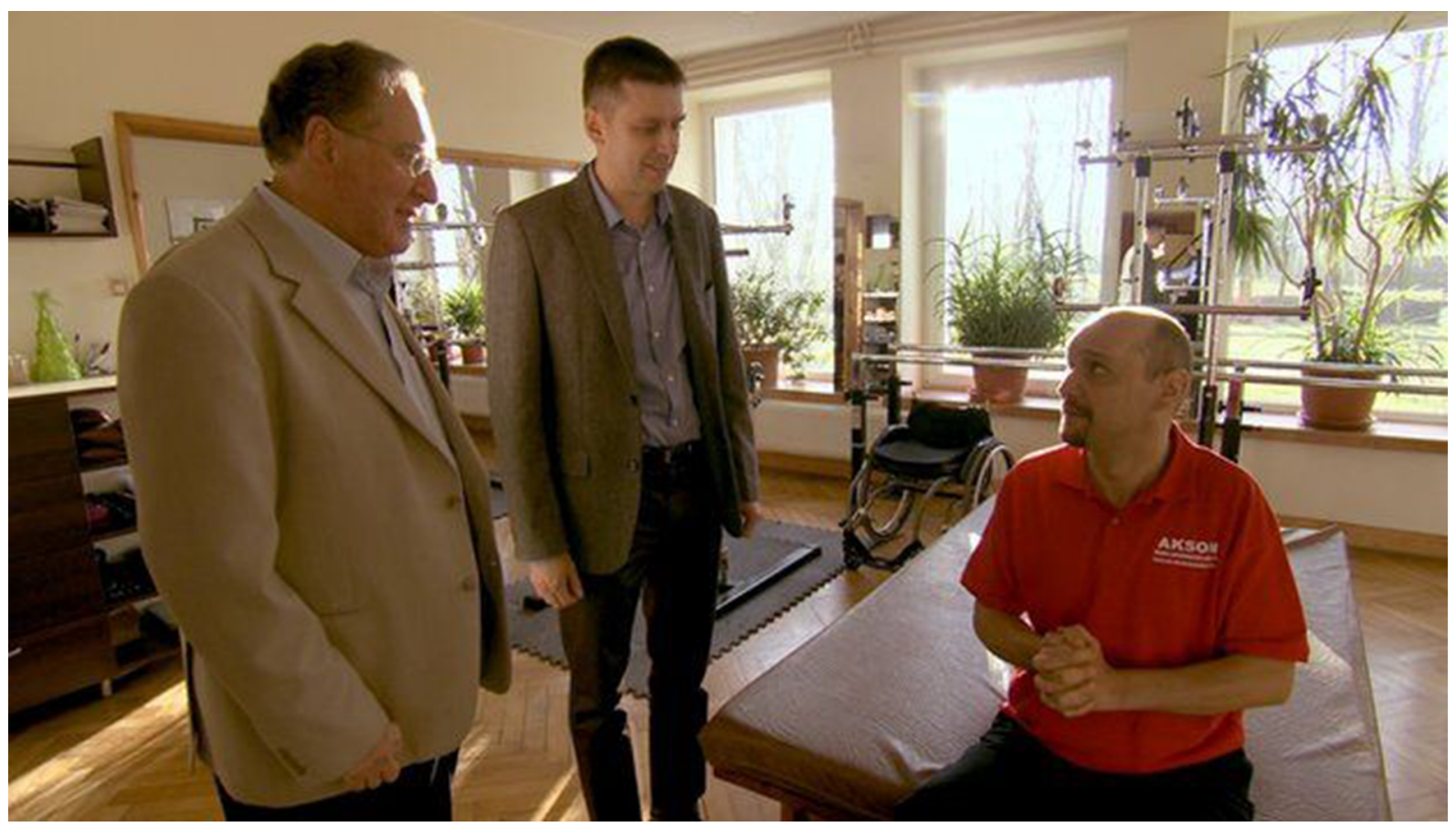

Figure 6 Geoffrey and Pawel Tabakow talking with the first patient in the world with a complete spinal cord transection, who recovered neurologically due to the innovative cell-nerve graft spinal cord reconstruction surgery. Photo taken at "Akson" Rehabilitation Center, Wroclaw, Poland, in 2014.

and showed a typical feature of Geoffrey - to see things in advance that others could not. According to Geoffrey and his main collaborators, Ying Li and Daqing Li, transplantation of OECs into the area of SCI should be the necessary precondition for axon regeneration. They also proved in an animal model, ${ }^{8}$ that bulbar OECs have stronger neurotrophic properties than the mucosal ones. My team showed additionally to this finding, ${ }^{7}$ that another necessary precondition for 
successful long-distance axon regeneration in the completely injured spinal cord is the removal of the glial scar together with bridging of the spinal cord gap with autologous peripheral nerves that could create endoneural channels guiding the regenerating central axons to their targets. This is how the exchange of ideas, cooperation, and friendship of two research groups enabled the elaboration of a new complex neurorestoration method with potential to become, in the future, a cure for SCI.

Looking back to my collaboration with Geoffrey I can say, that he was the most important person to inspire me and my team to begin experimental studies in patients with SCI. It is not something usual for a scientist to have so direct and remarkable an influence on the work of clinical specialists. I find this connection unique, because it enabled the direct translation of brilliant scientific ideas into practice. Yet this could not be possible without the extraordinary features of Geoffrey's character to inspire other people to explore unknown areas in medicine, to break well-established theories, to cross the borders of human imagination. Geoffrey was showing, in his daily work, that nature's laws are simple and logical, and strongly defeated any attempts of other scientists to complicate these laws. A clear example was his research showing that central neurons have the natural possibility to regenerate on condition that the pathways for their outgrowth are reestablished.

Geoffrey was often swimming against the tide. This was a feature that made our souls very close to each other. If I have to point to the most specific feature of Geoffrey as a personality that made him distinguishable, I would underline his honesty and love to other people. I am privileged and a lucky person to say that I knew Geoffrey, worked with him and most important - was his friend. I consider the fact that I knew Geoffrey as one of the most important professional and personal experiences in my life.

I believe that our teams will continue to implement successfully the scientific ideas of Geoffrey in the future to give hope and happiness to more patients suffering not only from SCI, but also glaucoma, optic nerve lesions, stroke and other diseases of the CNS. I believe that this is what Geoffrey expects from me and all his collaborators - to continue his work. In his last mail to me, sent January 13, 2017 Geoffrey asked me when a particular patient with SCI will come to Wroclaw for the new experimental treatment. He did not say any word about his suffering and illness. He was committed to the end to our new clinical study - "The Wroclaw Walk Again Project". My answer is: very soon Geoff, we will win, as we usually do.

\section{My best friend and most respected scientist - from the concept of neuroplasticity/neurorestoratology to IANR}

Hongyun Huang

It is very hard for me to believe that Professor Geoffrey Raisman passed away a year ago. I often cannot help but remember his great contributions to cell therapy, especially OECs for central nervous diseases and damage; the discipline of neurorestoratology; and the IANR. Here I try my best to tell who he was in my eyes and heart on behalf of the IANR, alongside an article from some friends commemorating him. ${ }^{9}$

\section{When and why I knew him}

I first knew Geoffrey in 1997, when I was a visiting research Professor at the Department of Neurosurgery in NYU Medical Center. At that time, I visited Professor Paul Cooper in clinic and Professor Wise Young (Wise, currently in Rutgers University, New Brunswick, NJ, USA) in his research laboratory. I eagerly wanted to explore some new methods which could help patients with SCI during my visiting time. Wise recommended I read the paper about OECs for SCI published by Geoffrey's team. ${ }^{2}$ He thought that these kinds of cells might help patients with SCI in clinic, in the future. Simultaneously, Wise suggested to me that I read more papers published by Professor Franklin (University of Glasgow, Glasgow, UK), ${ }^{10}$ Professor Ramon-Queto's (International Center of Regenerative Medicine, Valencia, Spain), ${ }^{11,12}$ Professor Doucette (University of Saskatchewan, Saskatoon, Canada) ${ }^{13-15}$ and others regarding OEC. I was deeply impressed with Geoffrey's OEC research work for SCI, so Wise and I decided to do OEC transplantation for contusion $\mathrm{SCI}$ in a rat model. Our experiment results showed that OEC could help axons ' regeneration, remyelination and recovery of partial neurological functions in this injury model, which was the most common SCI type in patients.

\section{Geoffrey and I became friends}

I began to do clinical OEC transplantation for complete chronic SCI first in the world in 2001, when I came back from Wise's laboratory. The preliminary result in this clinical study of patients with complete chronic SCI showed gradual functional recovery starting in a few days after OEC transplantation and were beyond my expectation and that of the professionals in the field. When I reported it in Chinese Medical Journal and attended meetings, this unexpected phenomenon started an extensive debate in international 
professional circles. ${ }^{16-18}$ During this period, Geoffrey and Ying Li visited our wards and talked with patients who had received OEC transplantation (Figure 7); Geoffrey and I have broadly exchanged our opinions about OEC and SCI, I was deeply impressed with his profound wisdom and extensive knowledge in this field. Even though we had some different opinions, both of us believed that cell therapy, especially with OEC, would be a very promising method for treatment of patients with SCI and other nervous diseases or damage. Our common expectations were to encourage more cell therapies including OEC to be translated into clinical studies or trials at that time. Actually, Geoffrey as one of the most important scientists, tried his best to encourage and collaborate with clinicians to assess the outcome of OEC intervention for SCIs and accept their recommendations. I am deeply sorry that he could not do OEC clinical trial in the UK before he died, although he really would have liked to see it done and had been trying with his best effort to achieve it. Fortunately, he collaborated with Polish colleagues to do what he most wanted to do in his life, and got the results he wanted.

\section{Setting up neurorestoratology discipline}

In the early years of first decade of 21 st century, the majority of neuroscientists doubted the clinical therapeutic value of cell therapy including OEC for neurological functional recovery in central nervous diseases or damage. On the other hand, there are many methods exploring neurologi- cal functional recovery, which include cell therapy, neurostimulation or neuromodulation, neurorestorative surgery, tissue engineering and bioengineering, medicine and etc. I discussed with Geoffrey, Wise, Wagih ElMasry (Keele University, Keele, UK), Kwok-fai So (Hong Kong University, Hong Kong, People's Republic of China), Tiansheng Sun (PLA Army General Hospital, Beijing,People's Republic of China), Lin Chen (Tsinghua University Yuquan Hospital, Beijing, People's Republic of China), Dajue Wang (Stoke Mandeville Hospital, Aylesbury, UK), Zaid Al-Zoubi (Jordan Ortho and Spinal Center, Amman, Jordan), Gustavo Moviglia (Maimonides University, Buenos Aires, Argentina), Enzhong Liu (Harbin Medical University, Harbin, People's Republic of China), Alan Mackay-Sim (Griffith University, Brisbane, NSW, Australia), Almudena Ramon-Cueto, Xijing He (Xi' an Jiaotong University, Xian, People's Republic of China), Jianjun Li (China Rehabilitation Research Center, Beijing, People's Republic of China), Zuo Luan (Navy General Hospital of PLA, Beijing, People's Republic of China), Shiqing Feng (Tianjin Medical University, Tianjin, People's Republic of China), Shaocheng Zhang (Changhai Hospital, Shanghai, People's Republic of China), Ying Li, Paul R Sanberg (University of South Florida, Tampa, Florida, USA), Hari Shanker Sharma (Uppsala University, Uppsala, Sweden), Milan R Dimitrijevic (Baylor College of Medicine, Houston, TX, USA), Ali Otom (King Hussein Medical Centre-RJRC Amman, Jordan), and more respected experts in this circle. I

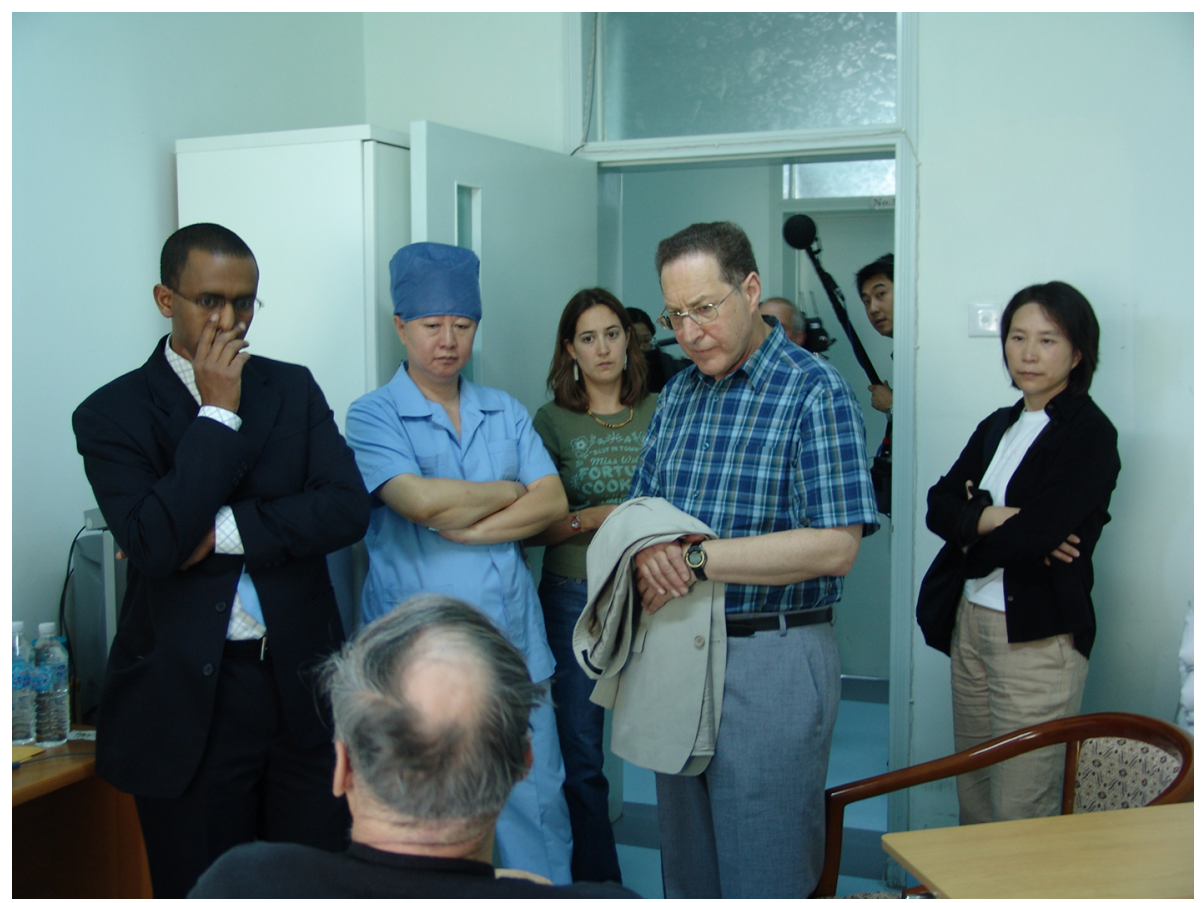

Figure 7 Geoffrey Raisman and Ying Li with a BBC reporter visited Beijing Rehabilitation Hospital of Capital Medical University, and talked with patients who had received olfactory ensheathing cells transplantation in 2005. 
was happy to meet these respected experts who are the founders of the neurorestoratology discipline. Most importantly, I got Geoffrey's very strong, firm support and many good suggestions at that time. Geoffrey and I further discussed the issue of what this new discipline should be named. It could be named as neuroregeneration, neurorestoration, neural repair, neurorestoratology, etc. Considering that the mechanisms of neurological functional recovery were composed of neuroregeneration, neural repair, neurostimulation or neuromodulation, neuroreplacement, neuroprotection, neuroplasticity, immunomodulation and others, the name "neuroregeneration" was too narrow; "neural repair" was possible to be misunderstood as structural repair; "neurorestoration" was easy to be misunderstood as a therapeutic neurorestorative method or mechanism. So, Geoffrey suggested "neurorestoratology" was better.

\section{Pushing neurorestoratology and IANR development}

Geoffrey encouraged in me that "a united team is much stronger than any single man" when we were discussing whether we should set up a special association in this field. Then the IANR was set up in 2007. With top worldwide experts' support in this field, such as Dafin F Muresanu (University of Medicine and Pharmacy of Cluj-Napoca, Cluj-Napoca Romania), Alok Sharma (LTM Medical College, Mumbai, India), Hooshang Saberi (Tehran University of Medical Sciences, Tehran, Iran), Shiqing Feng, and Gustavo Moviglia, the IANR annual conferences have been held for the last 10 years. Geoffrey participated in the first seven annual conferences (Figure 8), but was not able to participate in the eighth (2015) and ninth (2016) annual conferences as his doctor did not allow him to travel long distances, considering his health condition. At those two conferences, he wanted to present the topics "The problems in translating rat data to clinical injuries: numbers, retention, and scale" and "Fibroblasts of the olfactory nerve play a vital role in establishing OEC grafts". We lost the chance to listen and enjoy his wise and humorous speech.

We were very excited when "Beijing Declaration of International Association of Neurorestoratology" was approved by first IANR Council Board members in 2009 during the second annual conference. Its draft was written by Geoffrey, myself and 30 other experts from 18 countries. During the discussion, Geoffrey especially suggested that neurorestoration should emphasize close integration of neurorestorative and neurorehabilitative therapies, as well as the practice of clinical and preventative medicine to minimize complications of neural degeneration and damage in this declaration. ${ }^{19}$

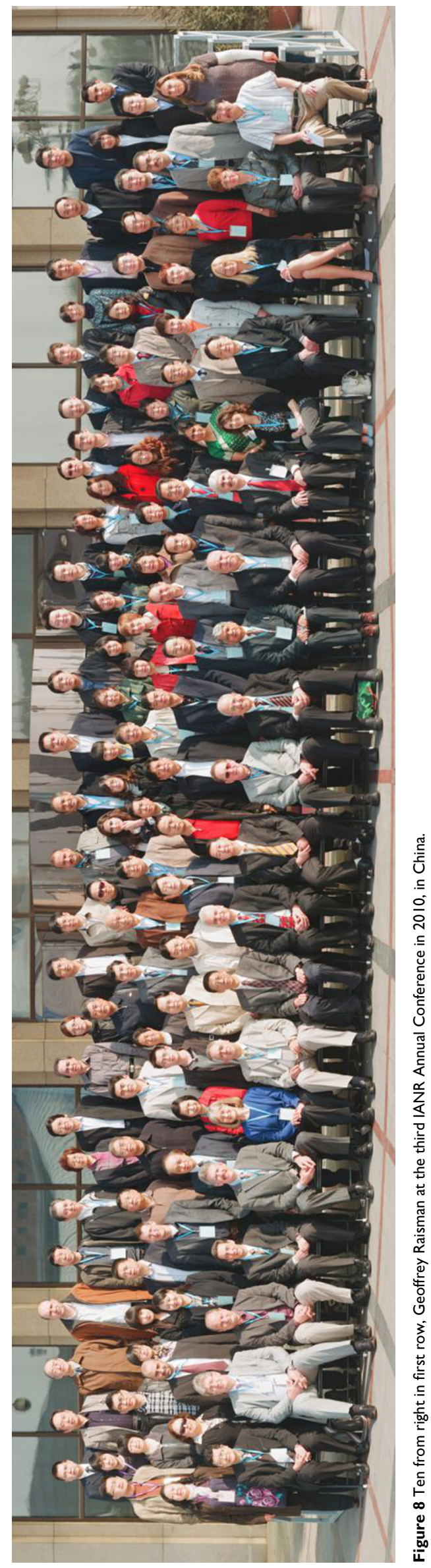




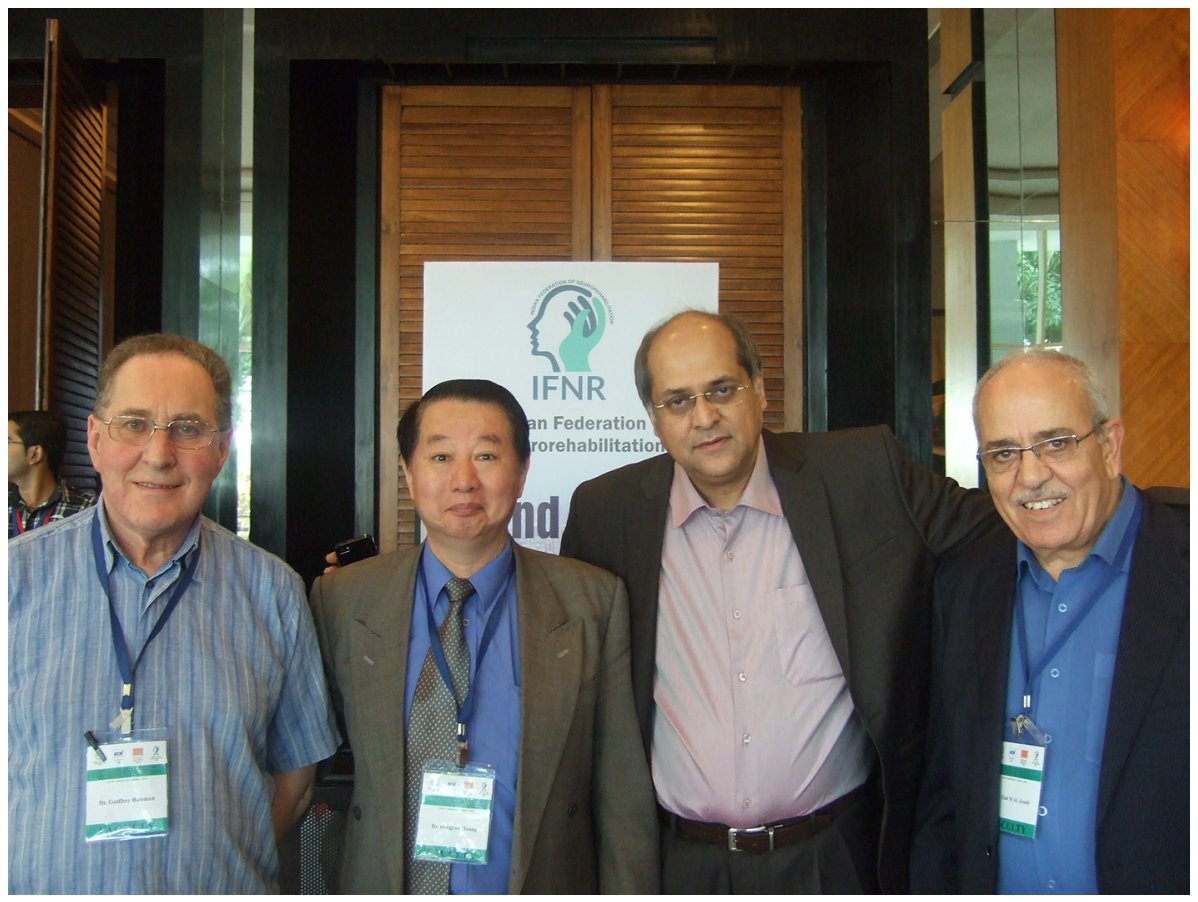

Figure 9 From left: Geoffrey Raisman, Hongyun Huang, Alok Sharma, and Zaid Al-Zoubi at the seventh IANR Annual Conference in India in 20 I4.

In the seventh IANR annual conference of 2014 in India, Geoffrey and I, as well as Ying Li had a long discussion on how to push the discipline and IANR development. We then communicated via email to express our ideas more clearly. Our discussion was focused on what the IANR's responsibilities were in addition to holding the annual conference. He emphasized that IANR should: 1) summarize and report the evidences of clinical neurorestorative positive results in the name of IANR, such as periodically releasing professional consensus for clinical positive therapeutic results; 2) set up the therapeutic standard of neurorestorative methods; 3 ) set up clinical neurorestorative therapeutic guidelines for nervous diseases and damage; 4) be the forefront platform that presents future advances beyond those already achieved; 5) organize the journal/book publication; 6) train and encourage young scientists and physicians to be interested in the neurorestoratology discipline. All were the IANR's responsibilities. And the most important was that currently those responsibilities only could be done by the IANR. Very regrettably, I never realized that the talking between Geoffrey and myself in India was our physical eternal farewell (Figure 9).

After the India conference, even if Geoffrey was sick, he still kept pushing the development of neurorestoratology and IANR. Geoffrey, myself, Paul R Sanberg, Hari Shanker Sharma and Lin Chen finished compiling and publishing the two-volume textbook Neurorestoratology (Figure 10) by Nova Publisher in $2015,{ }^{20}$ which is the first professional specialized book in the field of the neurorestoratology. With support of all IANR council board members, editorial board members and experts in this field, the IANR official journal Journal of Neurorestoratology has been included in the Emerging Sources Citation Index (ESCI) by Thomson Reuters Web of Science Content since 2016.

\section{Summary and IANR action}

From putting forward the theory of neuroplasticity ${ }^{1}$ in Geoffrey's early life, to his being one of the most important founders of neurorestoratology, neuroplasticity (one of the neurorestorative mechanisms ${ }^{21}$ ) is like a seed of neurorestoratology in his heart, which has now grown into a big tree.

Geoffrey's death is a huge loss for the discipline of neurorestoratology and the IANR. To promote the development of neurorestoratology and the IANR is his unfinished professional goal; as a way for us to commemorate him, the IANR in the fourth Council Board meeting, decided to establish the Raisman Neurorestoratology Foundation, which will support the clinical multicenter neurorestorative therapeutic trials or studies and award the winner of Raisman Youth Forum. Also, IANR will publish this paper commemorating him in the Journal of Neurorestoratology. All IANR members will try our best to complete his expectation, that is: to make neurorestoratology more widely recognized; to make IANR a stronger association; to make the Journal of 


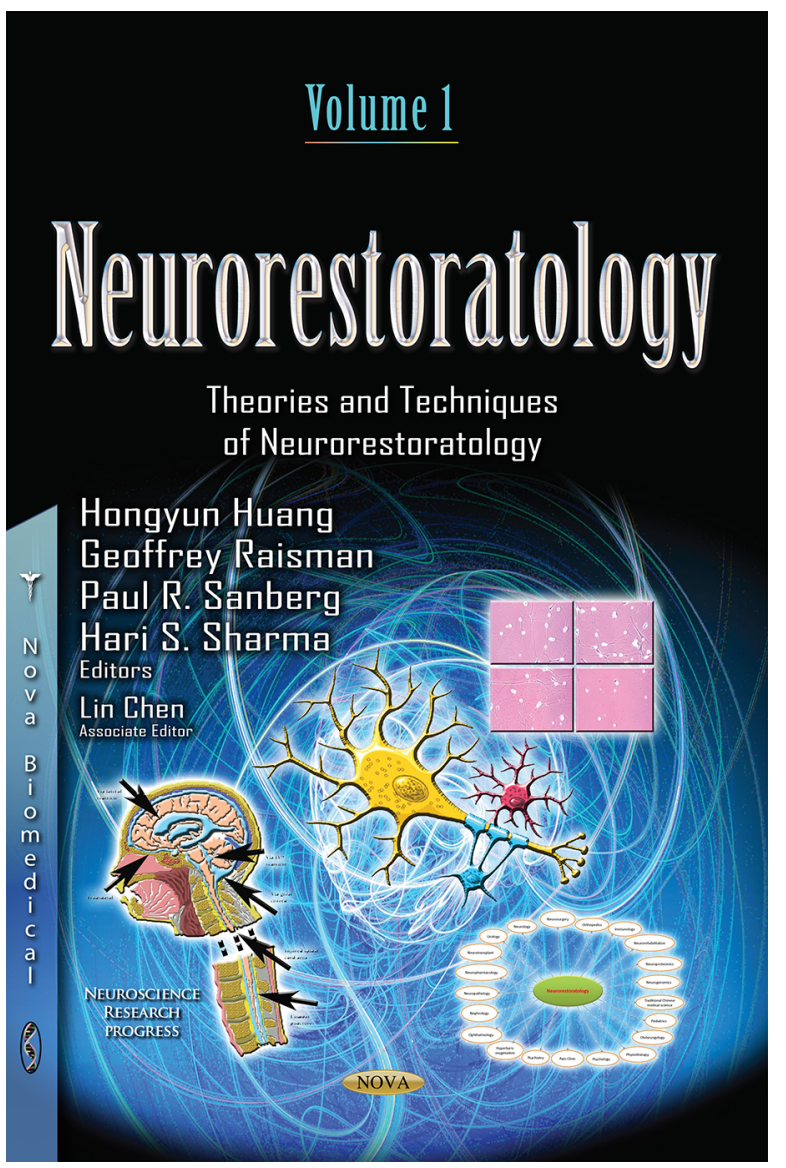

Figure 10 Two volume textbook, Neurorestoratology was published in 2015. Cover imaged reproduced with permission from Nova Science Publishers, Inc. ${ }^{20}$

Neurorestoratology have higher impact factors; to explore more effective neurorestorative therapies and let patients benefit more from our hard work. So neurorestoratology and IANR have a long way to go. The goal is laid ahead, but the road is at the feet.

Lastly, I want to share again Geoffrey's "Welcome Address to the Delegates of the Tehran Meeting of the International Association of Neurorestoratology", which may allow readers to better know him, and understand his noble character and realm.

It is a great pleasure and a great honor to welcome the delegates at the Tehran Meeting of the International Association for Neurorestoratology.

From its small original foundation by Professor Huang in Beijing, the Association is going from strength to strength, including more and more countries, and we warmly welcome all new members.

Thank you Professor Saberi, my dear old friend, Hooshang, for your generous hosting. I embrace you. Salaam.
It is a great sadness for me that I am unable to attend.

I look forward to hearing of new advances, and to being with you all next year.

Here, far from your cheerful, friendly voices, here, where all is quiet, undistracted by the excitement, by the day to day busy, crowded halls of the meeting, I am able to see our purpose more clearly.

For the heart of the matter requires only one word. That word is hope.

It is not our small hopes, it is not your hopes and mine, of which I speak, but the hope of millions of people, people suffering around the world. People who have no voice, people in the dark grip of relentless damage to their brains and spinal cords, people who must suffer and see their loved ones suffer in silence. It is a terrible silence.

We carry on our shoulders their hopes of a better future.

Yours is a noble task, and not an easy one.

You carry a fragile, precious vessel.

I wish you, my dear friends and colleagues, every success in lightening the burden of others, and in bringing dawn. Dawn to a long and endless night.

Bidrud.

\section{Disclosure}

The authors report no conflicts of interest in this work.

\section{References}

1. Raisman G. Neuronal plasticity in the septal nuclei of the adult rat. Brain Res. 1969;14(1):25-48.

2. Li Y, Field PM, Raisman G. Repair of adult rat corticospinal tract by transplants of olfactory ensheathing cells. Science. 1997; 277(5334): 2000-2002.

3. LiY, Li D, Ying X, Khaw PT, Raisman G. An energy theory of glaucoma. Glia. 2015;63(9):1537-1552.

4. Raisman G. The Undark Sky: A Story of Four Poor Brothers. Harehills Press. 2002.

5. Raisman G. Specialized neuroglial arrangement may explain the capacity of vomeronasal axons to reinnervate central neurons. Neuroscience. 1985;14(1):237-254

6. Tabakow P, Jarmundowicz W, Czapiga B, et al. Transplantation of autologous olfactory ensheathing cells in complete human spinal cord injury. Cell Transplant. 2013;22(9):1591-1612.

7. Tabakow P, Raisman G, Fortuna W, et al. Functional regeneration of supraspinal connections in a patient with transected spinal cord following transplantation of bulbar olfactory ensheathing cells with peripheral nerve bridging. Cell Transplant. 2014;23(12): 1631-1655.

8. Ibrahim A, Li D, Collins A, Tabakow P, Raisman G, Li Y. Comparison of olfactory bulbar and mucosal cultures in a rat rhizotomy model. Cell Transplant. 2014;23(11):1465-1470.

9. Sanberg PR. Geoffrey Raisman, 1939-2017: “Opening a Scientific Door and Giving Hope" Cell Transplant. 2017;26(5):733-734.

10. Franklin RJ, Gilson JM, Franceschini IA, Barnett SC. Schwann cell-like myelination following transplantation of an olfactory bulb-ensheathing cell line into areas of demyelination in the adult CNS. Glia. 1996; 17(3):217-224 
11. Ramón-Cueto A, Nieto-Sampedro M. Regeneration into the spinal cord of transected dorsal root axons is promoted by ensheathing glia transplants. Exp Neurol. 1994;127(2):232-244.

12. Ramón-Cueto A, Valverde F. Olfactory bulb ensheathing glia: a unique cell type with axonal growth-promoting properties. Glia. 1995; 14(3): 163-173.

13. Doucette JR. The glial cells in the nerve fiber layer of the rat olfactory bulb. Anat Rec. 1984;210(2):385-391.

14. Doucette R. PNS-CNS transitional zone of the first cranial nerve. J Comp Neurol. 1991;312(3):451-466.

15. Devon R, Doucette R. Olfactory ensheathing cells myelinate dorsal root ganglion neurites. Brain Res. 1992;589(1):175-179.
16. Huang $\mathrm{H}$, Chen $\mathrm{L}$, Wang $\mathrm{H}$, et al. Influence of patients' age on functional recovery after transplantation of olfactory ensheathing cells into injured spinal cord injury. Chin Med J. 2003;116:1488-1491.

17. Cyranoski D. Fetal-cell therapy: paper chase. Nature. 2005;437:80-81.

18. Watts J. Controversy in China. Lancet. 2005;365:109-110.

19. IANR (International Association of Neurorestoratology). Beijing Declaration of International Association of Neurorestoratology (IANR). Cell Transplant. 2009; 18:487.

20. Huang H, Raisman, G, Sanberg PR, Sharm HS. Neurorestoratology. New York. Nova Science Publishers; 2015.

21. Huang H, Chen L. Neurorestorative process, law, and mechanisms. Journal of Neurorestoratology. 2015;3:23-30.

Dove Medical Press encourages responsible, free and frank academic debate. The content of the Journal of Neurorestoratology 'Editorial' section does not necessarily represent the views of Dove Medical Press, its officers, agents, employees, related entities or the Journal of Neurorestoratology editors. While all reasonable steps have been taken to confirm the content of each Editorial, Dove Medical Press accepts no liability in respect of the content of any Editorial, nor is it responsible for the content and accuracy of any Editorial.

Journal of Neurorestoratology

\section{Publish your work in this journal}

The Journal of Neurorestoratology is an international, peer-reviewed, open access online journal publishing original research and review articles on the subject of Neurorestoratology. To provide complete coverage of this revolutionary field the Journal of Neurorestoratology will report on relevant experimental research, technological advances,

\section{Dovepress}

and clinical achievements. The manuscript management system is completely online and includes a very quick and fair peer-review system, which is all easy to use. Visit http://www.dovepress.com/testimonials. php to read real quotes from published authors. 